\title{
La Centralidad del Discurso del 'Héroe' en la Construcción del Mito Nacional: una lectura de la historiografía conservadora desde el género ${ }^{1}$
}

\section{LORENA ARIMIJO G. ${ }^{2}$}

\begin{abstract}
Resumen
La idea de Chile como nación unitaria, que construye el relato historiográfico conservador, se fundamenta en una construcción integradora de la relación entre el colectivo y determinados sujetos que, bajo el supuesto de una patria demandante de deberes, construye la solidaridad por la acción sagrada de uno de los suyos, el héroe nacional, quien es capaz de llegar a la inmolación personal con el fin de proteger a la comunidad. La tríada virilidad-héroe-nación, unida a la imagen de un sujeto fundacional o sacrificial, aparece como un ordenamiento simbólico que asegura la trascendencia de la nación y, a través de ésta, la inmortalidad del héroe, quien resuelve mágicamente la contradicción imaginaria de la comunidad respecto a su cosmogonía. La perdurabilidad de la nación se garantiza mediante el uso de la violencia, y la intimidación hacia un otro fuera del colectivo, lo que asegura el ejercicio de la solidaridad interna del grupo. Así, la acción del héroe permite la transición de un pasado internamente conflictivo hacia un futuro entendido como un proyecto particular que asegura la continuidad de la nación y su proyección histórica. La historiografia conservadora, en definitiva, lee la historia de Chile como relato religioso de constitución de una nueva estirpe que revaloriza el proceso de independencia como construcción de una nueva legitimidad, donde el último del antiguo orden (con Bernardo O’Higgins como el huacho ilegítimo) se convertirá en el primero de la nueva estirpe; proceso de sacralización que encuentra su apogeo en la interpretación conservadora sobre Arturo Prat, donde la estirpe (chilena) ya consolidada desea para América los valores superiores que ella ha instaurado.
\end{abstract}

\begin{abstract}
The idea of Chile as an unitary nation, that is built by the historiographical conservative discourse, is fundamented in the integrating construction of the relation between the collective and specific subjects which, under the supposition of a motherland demanding duties, constructs solidarity by the sacred action of one of its own, the national heroe, who is capable of reaching personal sacrifice with the aim to protect the community. The triade virility-heroe-nation, linked to the image of a founding or sacrificing subject, seems like a symbolic ordering that assures the transcending of

El presente documento constituye una revisión de la tesis de grado "La construcción del discurso nacional desde el discurso de género en la historiografia conservadora chilena" realizada el año 2005. El tiempo ha permitido afinar el argumento y conceptos. De este modo, el presente texto es un reporte de una investigación ya realizada, pero que continúa hoy en marcha por la fertilidad del objeto de estudio.

Socióloga y Mag. Gerencia Pública, Universidad de Chile. Estudiante de doctorado en sociología, Univ. Complutense de Madrid. Investigadora del Núcleo de Género, Universidad de Chile.
\end{abstract}


nation and, through this, the inmortality of the heroe, who solves magically the imaginary contradiction of the community regarding its cosmogony. The unperishableness of nation is garanteed through the use of violence, and intimidation towards an "other" out of the group, which assures the exercise of the group's internal solidarity. Therefore, the action of the heroe allows the transition from an internally conflicted past towards a future, meant as a particular project that assures the continuity of nation and historic projection. The conservative historiography, definitely, reads the history of Chile as a religious tale about the constitution of a new lineage that revalues the process of independence as constrution of a new legitimacy, where the last of the old order (with Bernardo O'Higgins as the ilegitimate son - "huacho") will turn into the first of the new lineage, sacralization process that finds its peak in the conservative interpretation about Arturo Prat, where the (Chilean) lineage already consolidated, wishes for Latin America the superior values that has already installed.

\section{Introducción}

Cuando se acerca aceleradamente la conmemoración por los doscientos años del proceso que abrió la ruta de lo que se suele conocer como independencia y que desembocó en la configuración de la vida republicana en Chile, han comenzado a elaborarse diversas celebraciones y ritos públicos que intentan revivir, revisar o recordar ese período con el fin de preservar en la memoria una parte significativa de nuestra identidad colectiva y que comenzó a producirse en torno a la idea de la nación chilena. Justamente este tema ha sido uno de los que ha tenido mayor divulgación pública, siendo recreado por diversos medios de comunicación y renombrado por diferentes actores políticos. De particular relevancia en esta mirada retrospectiva es el recuerdo de figuras consulares, sujetos relevantes que portan la construcción de la nación, de la identidad o que constituyen pilares insoslayables en la comprensión del proceso de instauración de la comunidad política. Un rol decisivo cumplen aquí las figuras heroicas, que portan un carisma en lo militar y en lo espiritual, siendo el primero condición del éxito del proyecto y siendo el segundo la conciencia misma del proyecto.

Los relatos de los historiadores han sido fundamentales en la construcción de la idea de nación y su contexto histórico. De particular relevancia serán las escuelas historiográficas que se impusieron en la construcción de la historia oficial y que, con el poder de la institucionalización de sus miradas, han influido en la construcción de imaginarios referidos a la nación, la identidad y el destino colectivo. Esta creación -directa o indirecta- de la idea de nación puede observarse con regularidad en un determinado enfoque epistemológico que por largo tiempo ha monopolizado la 'verdad' histórica y que se conoce con el nombre de 'historiografía conservadora' ${ }^{3}$. Aquí dicha 'verdad'

El pensamiento historiográfico conservador chileno presenta un marco conceptual relativamente homogéneo que ensalza nociones como la tradición, la autoridad, la continuidad histórica, el orden y la nación; mientras que se opone fuertemente al debate del liberalismo, la democracia o el comunismo, aunque en estos últimos contenidos 
la Centralidad del Discurso del "Héroe" en la Construcción del Mito Nacional: una Lectura de la Historiografía Conservadora desde el Género / Lorena Armijo G.

se articula con las obras y proezas de grandes hombres que merecen ser recordados y enaltecidos por la historia. Para el caso chileno, esta historiografia ha recurrido a figuras extraordinarias que portan el espíritu de la nación, siendo uno de ellos el "héroe nacional", figura que llega a encarnar los valores patrios o morales del país ${ }^{4}$ y que se constituye en una especie de sustento simbólico de la nación, que se ratifica en su actuación como 'estabilizadores de carácter nacional'5 y como referente de la solidaridad comunitaria y de la comunidad política chilena. Es tal la centralidad de la figura del héroe en la historiografia conservadora, que se han escrito obras paradigmáticas destinadas a relatar e interpretar las biografias de los "padres de la patria" y sus rasgos heroicos.

En las imágenes de los héroes constructores de la nación, los historiadores conservadores articulan formas de sentido que orientan a los/as chilenos/as y le otorgan marcos de significados a sus creencias, conductas y acciones. El héroe se sitúa no sólo como constructor de la identidad nacional, sino además como referente de la identidad personal. La trascendencia de este discurso social radica en el uso de determinados códigos, asociaciones, relaciones y jerarquías que suponen la posición (implícita) de cada individuo en la vida social y una ordenación del mundo dentro de uno o varios esquemas que actúan como puntos de referencia y que no se restringen únicamente a las definiciones y valores en torno a la identidad nacional, sino que llegan a instalarse en complejos entramados simbólicos que asignan valores y patrones de conducta a imagen y semejanza del héroe nacional.Vale decir, en dicha figura también se delinea el ser hombre y el ser mujer con las virtudes (y debilidades) que ello supone. En él se destaca, por ejemplo, la fuerza y templanza masculina y la solidaridad femenina. Pero no sólo hay asociaciones y jerarquías a partir de marcos valorativos de lo femenino y lo masculino. La relevancia de esta diferencia cultural radica en la capacidad de trascender de estas asociaciones, constituyéndose los valores masculinos en articuladores de la salvación de la comunidad y de la construcción exitosa de la comunidad política. Por su parte, los valores femeninos asociados exclusivamente a lo maternal suelen ser colaboradores en la conformación del proyecto nacional, y cuando escapan a esto representan instancias de decadencia del proyecto nacional. Esta proyección constituye en gran medida el objeto del presente análisis y encuentra en el héroe un objeto específico y privilegiado de esta densidad simbólica.

Desde esta conjetura es que resulta necesario indagar la figura del héroe nacional y su relación con la construcción de la idea de nación chilena, identificando y comparando los elementos constitutivos del héroe con aquellos que emergen en el discurso

o aspectos encontramos una heterogeneidad en sus planteamientos comunes: para unos historiadores, dicho debate se centrará en una línea argumentativa nacionalista que favorece la presencia de un sistema autoritario y centralizado de gobierno; mientras que otros, privilegiarán una perspectiva corporativista que contempla la presencia de instituciones (como gremios y profesiones) que vienen a controlar el excesivo control del poder político que tiene el Estado. (Véase, Cristi y Ruiz, 1992).

Véase a Salazar, Gabriel y Pinto, Julio (1999).

Véase a Godoy, Hernán (1976). 
de la nación que provee la historiografia conservadora chilena. Asimismo, es por esta articulación cultural que resulta significativo identificar la identidad de género que subyace en la idea de nación.

Este trabajo pretende rastrear el acoplamiento de dos grupos de significaciones sociales que a primera vista parecen estar separadas. En este caso, cómo la nación -mediada en gran parte por el concepto de héroe- se construye en un nivel distinto, pero de algún modo subsidiario a las significaciones de género, mostrando de esta manera cómo la compleja identidad colectiva de la nación contiene no sólo los evidentes contenidos políticos e integrativos, sino que también traduce en un nivel distinto y particular ciertas significaciones de género que son socializadas y aprendidas como verdaderas y naturales y que tienden a perdurar en el tiempo.

Para conseguir la comprensión de este fenómeno, la historiografia conservadora chilena emerge como una fuente de investigación por excelencia. Es indudable que ella es parte de dinámicas de construcción simbólica de la nación, dado que está fuertemente vinculada a la constitución de la institucionalidad chilena. Y no sólo esto, sino que además cumple un rol significativo en la reproducción cultural que supone el proceso educativo, siendo esta historiografia la base sobre la cual se han elaborado los textos escolares que han estudiado todos/as los/as ciudadanos/as chilenos/as durante varias décadas debido a su inclusión en los programas educativos oficiales de historia.

En particular, hemos escogido dos obras que abordan la cuestión del héroe a partir dos personajes centrales en la Historia de Chile: Bernardo O'Higgins y Arturo Prat. El primero corresponde a la obra titulada “O'Higgins”, escrita por el historiador chileno Jaime Eyzaquirre; mientras que el segunda libro es "Arturo Prat", de Gonzalo Vial Correa. Ambos historiadores fueron fieles exponentes de la conservación de la autoridad y tradición chilena. Más aún, ambas obras no son meras biografias con sensibilidad histórica, sino que constituyen claros discursos de la vinculación irrestricta de los respectivos héroes con el devenir colectivo y espiritual de la nación.

\section{La construcción de la nación en manos del héroe}

Cabe precisar que la lectura sociológica de las obras de Eyzaguirre y Vial Correa supone un tratamiento de esos textos en tanto discursos. No se les entiende desde su objetividad, por lograda que pudiera estar, sino desde sus posiciones sociales y sus efectos ideológicos. Fundamentalmente interesa apreciar cómo ambos autores interpretan el carácter heroico de determinados personajes históricos como características de trascendencia política, espiritual y cultural. De este modo, es posible dar cuenta de reconstrucciones de los imaginarios de nación y héroe, al tiempo que es viable generar un conjunto de hipótesis sobre el sentido de conceptos auxiliares a los discursos principales. En definitiva, el análisis del discurso historiográfico conservador consti- 
la Centralidad del Discurso del "Héroe" en la Construcción del Mito Nacional: una Lectura de la Historiografía Conservadora desde el Género / Lorena Armijo G.

tuye en sí mismo un material de gran relevancia para comprender la forma en que se articula el proyecto de construcción de una cultura política específica.

En la reconstrucción de la idea de nación, sus diferentes discursos públicos nos entregan una noción fuertemente homogénea y consistente que se acentúa en la práctica social como un fenómeno altamente integrador y articulador de colectivos distintos. No obstante, si analizamos dicha idea en los textos revisados y sobre los cuales se han construido esos discursos públicos, veremos que el concepto de 'nación' oscila entre dos polos que conjuntamente le potencian. En efecto, bajo el imaginario del héroe nacional es posible observar la ocurrencia sistemática de una tensión simbólica entre la dimensión 'violenta' que despliega dicho actor en toda su masculinidad guerrera y la dimensión 'solidaria' centrada en la comunidad nacional que el mismo relato propone. Esta tensión entre violencia y solidaridad, que se desprende de los textos historiográficos conservadores chilenos, nos remite al problema estructural de la semejanza y la diferencia, de lo propio y ajeno, categorías que finalmente conforman aspectos disonantes y ambivalentes de la identidad nacional chilena.

Es en la tensión entre violencia y solidaridad donde la presencia del héroe resulta crucial. Su rol consiste en transmutar la diferencia interna en semejanza, al tiempo que garantiza una demarcación con lo que será llamado ‘externo', extranjero. El héroe produce una síntesis que, conteniendo las diferencias, permite disolverlas o trascenderlas. Al respecto resulta útil analizar los textos del discurso historiográfico conservador desde los ejes señalados:

a) Polo Violencia:

En el campo de batalla los héroes dan a conocer su condición singular y extraordinaria, esto es, su heroísmo. Ellos expresan en la arena bélica su principal cualidad humana que es la virilidad, expuesta en el despliegue de su fuerza y agresividad en el enfrentamiento con sus enemigos. El discurso más potente de un héroe es el referido a la violencia y a la destrucción del otro que es adversario, del antagonista fuera del colectivo (y que se constituye como obstáculo y riesgo para ese colectivo).Aquí el uso de la violencia aparece como un medio de disuasión porque logra perseguir que los 'otros' (sus soldados y enemigos) obedezcan sus órdenes. Esto le permite ir creando y estructurando relaciones en las que prevalece una nítida verticalidad entre él y el resto de los soldados, utilizando la violencia como instrumento de control. Es una manera de afirmar su masculinidad, de perpetuarla y delimitar su dominación ${ }^{6}$. Justamente, el héroe -al estar en constante peligro fisico-, va evidenciando su carácter atrevido. Esto nos recuerda la sentencia de Clausewitz relativa a que ni el valor ni el entusiasmo hacen un héroe militar, sino la guerra misma, su destreza en la lucha, las pruebas y victorias, los sufrimientos aceptados y superados.

Véase Connell, Robert (1997). 
Si bien es cierto que hay un énfasis en el carácter violento del héroe en los textos revisados, su ubicuidad queda más bien supeditada a la creación de la nación, siendo su medio más eficaz, en tanto, para el héroe sólo constituye una herramienta que llega a enaltecerlo. Es interesante observar que el desgaste simbólico o la pérdida de valores que suponen las guerras y batallas, llega -en la historiografia conservadora- a reemplazarse por un relato que incorpora al heroísmo otras cualidades. Esto surge en medio de (o justamente debido a) la ambivalencia que puede contener una historia donde la construcción de la nación supone la destrucción de otro. Esta dualidad se resuelve con la alegorización de los grandes valores de la nación como el sacrificio, la valentía, la inteligencia y la templanza. Más aún, la justicia, que es un valor distante de la vida armada convencional, aparece reivindicada. El héroe es tal en tanto está defendiendo una causa justa. Hay aquí una justificación de sus actos violentos, los que pasan a ser simplemente legítimos.

Así el heroísmo no es sólo uso de la violencia en defensa de colectivo, sino que también supone el mérito, la valentía, la rectitud y el honor, elementos que por cierto se despliegan en el campo de batalla y que son percibidos por todos quienes allí se encuentran. En particular, sus soldados (dirá el discurso) depositan en la figura del héroe su vida y los resultados de una batalla. Ellos saben de antemano que el héroe puede cambiar el curso de los hechos, puede transformar una posible derrota en una victoria definitiva. Este reconocimiento de los soldados es vivido como entrega íntima y llena de fe, que surgiría del entusiasmo del momento, de la amargura de la potencial derrota, del miedo al enemigo y de la esperanza en un cambio de la situación dramática en la que todos están sumergidos. Gracias a su heroísmo, él se constituye en un factor disruptor del (des)orden de la contienda debido a que entrega seguridad y amparo, al subvertir el momento caótico o sin esperanzas en un futuro cargado de sentido que los conduce a la victoria. De ahí que pueda pensarse que el héroe es un transformador espiritual que revoluciona la historia.

\section{b) Polo Solidario:}

En los textos revisados, el accionar del héroe no se fundamenta en una búsqueda o un deseo narciso y/o pecuniario, sino que hay una consagración personal en nombre del colectivo. Durkheim (1992) nos entrega algunos elementos que podemos sumar al análisis ${ }^{7}$. Él señala que al actuar del individuo en el mundo profano se sobreañade otro, que si bien no existe más que en su pensamiento, cuenta con una especie de dignidad más elevada que el mismo colectivo y que se representa en la conciencia común. Siguiendo el argumento del mentado sociólogo, podemos hacer una analogía -o al menos un vínculo- entre profeta y héroe a partir del rol simbólico de ambos. Al respecto, el héroe debe salir del sentido único y personal de su acción (vencedor en la Para Durkheim, en el marco de la secularización, y puesto que la religión representa a la autoridad moral del grupo, las sociedades modernas se ven necesitadas de desarrollar lo que él, siguiendo a Rousseau, denomina "religiones civiles", que son precisamente los sentimientos nacionales y nacionalistas. Agradezco a Daniel M. Giménez este comentario y su precisión. 
La Centralidad del Discurso del "Héroe" en la Construcción del Mito Nacional: una Lectura de la Historiografía Conservadora desde el Género / Lorena Armijo G.

lucha armada), siendo exhortado -en virtud de los ideales de su grupo- a desplazar el sentido profano de sus intereses (obtención de prestigio, botines, u otros privilegios) con el fin de entregarse exclusivamente a la 'salvación' del colectivo. Lo anterior nos lleva a suponer que el héroe se constituye en una versión secularizada del profeta, más aún, adelantaremos que en su construcción simbólica, nación y comunidad religiosa son lo mismo, aunque con distintos contenidos (o fuentes).

Pero dicha transición supone un proceso de violencia simbólica, donde la transformación oculta la forma primitiva de los valores. Mayol (2005) dice que la nueva configuración del sistema de valores en un naciente orden de sentido supone una transmutación cuya sustancia originaria se hace desconocida o secreta. En este sentido, a través de la acción del héroe, muere lo profano y renace lo sagrado bajo una nueva forma, sucumbe el individuo y prorrumpe el colectivo bajo la idealización de la nación.

En la emergencia de esta transvaloración, el heroísmo surge como un 'renacimiento', un proceso de 'purificación' que parte de la convicción de la 'revelación de la verdad's como sentido histórico que debe regir la nación y su destino. La conquista de la verdad 'alumbra' el camino que el héroe debe seguir, otorgándole una nueva significación y legitimación para actuar a futuro en función de la certeza. Así esta 'claridad' le impide al héroe conducirse de otra manera, no podría evitar su destino, porque ellos (los héroes) conocen el sentido de la historia, saben por dónde tiene que conducir a la nación. La idea de 'llamado' también remite a la idea de la vinculación con lo supraterrenal: el colectivo demanda el actuar del héroe en determinado momento y lugar para cambiar el rumbo histórico de la nación, para la transformación, ruptura o el salto que el grupo requiera. Con todo, el héroe es en este sentido un ser providencial.

El mensaje de la 'verdad' se refiere a la importancia de ser (el héroe) el protector de la tierra nacional y/o de su libertad o soberanía y la de su gente y el cuidador de los bienes nacionales para el futuro en paz de las nuevas generaciones. Desde una interpretación religiosa la aceptación de este llamado que hace el héroe en el discurso historiográfico conservador aparece como una declaración de confianza y de entrega a la Divina Providencia como constructora final de la nación, siendo ella la que guía sus actos y emprende junto a él la victoria. La fe del héroe llega a trascender los dogmas religiosos y se encarna en él de manera similar a la fe vivida por otros tan hombres extraordinarios como Abraham, San Pablo y Jesús, que se entregaron a los propósitos divinos.

Por esto, los héroes del relato historiográfico conservador chileno son encarnaciones de valores del colectivo, personajes ‘sagrados’ en quienes queda depositada la esperanza

\footnotetext{
Su inspiración proviene terrenalmente de un sabio o un maestro quien es el encargado de la renovación del carisma. Se trata, de una trasmisión de saberes que emergen como la conciencia absoluta y generalizada que el sentido de la historia pasa por el héroe. Es él quien vendría a asegurar la reproducción de la herencia de los ideales nacionales y de los bienes culturales desde una línea que necesariamente se presenta como masculina.
} 
del destino de la nación. Ellos emergen como el punto más alto en la dignificación de la nación, haciéndola 'invulnerable' en términos simbólicos e inexpugnable frente a aquellos que están fuera del colectivo. El héroe es guía profética y protección divina. Este argumento resulta central en los relatos analizados porque permite entender la muerte de un héroe en combate. En esos discursos jamás se duda de sus destrezas militares, sino que la muerte en combate es resignificada como una manifestación -plena de sentido- de su arrojo, o sencillamente como un acto de sacrificio.

Y esto no es menor porque la noción del sacrificio es un elemento central del imaginario de la nación que emerge en los textos historiográficos revisados. Aquí el héroe se convierte en tal por su inmolación para que el colectivo pueda seguir con su vida cotidiana, él realiza un acto de sacrificio por el bien superior de la comunidad. Si revisamos el concepto sacrificio nos debemos remitir a la creación de lo sacro, a la integración entre lo terrenal, lo profano y lo divino. Es la unión entre la comunidad y su trascendencia, lo perecedero y la continuidad. Únicamente mediante la institución del sacrificio del héroe, la comunidad -en su vida profana- puede acceder al mundo sagrado, porque la entrega sacrificial llega a ser un acto de ofrenda en la que se renuncia a la individualidad con el fin de construir un 'nosotros' que supone creencias y rituales de fuerza sagrada. En el sacrificio convergen aspectos de comunión entre los connacionales y su nación, llegando ésta a ser imaginada por sus integrantes como una comunidad intelectual y moral que todos comparten ${ }^{9}$. Justamente, la noción de sacrificio emerge como forma de demostración del carácter superior de la nación respecto a las biografias individuales. Los grandes hombres entienden que es más importante la patria que sus vidas, tal como ocurre con la interpretación que entrega la historiografia conservadora sobre el abordaje de Prat al Huáscar.

El rol sagrado del héroe permite entender una característica decisiva: ellos son el vínculo del presente con el pasado y la proyección de la nación hacia el futuro. El héroe es la operación de mediación entre la nación y su historia, en él no sólo se manifiesta, sino que se constituye el colectivo. El vínculo con el pasado se realiza en la relación de la historia personal del héroe con el país. En ese lazo hay una semejanza aparentemente inmanente entre el héroe y sus valores con la historia y los valores patrios, mientras que la proyección hacia el futuro la organiza y legitima el colectivo siguiendo los ritos y tradiciones que posibilitan la instalación pública del pasado mítico.

El discurso conservador instala la idea de que sin estos personajes la historia no se modifica, carece de sentido. Pero al mismo tiempo, la exclusividad y singularidad del héroe y la mirada de que toda la historia pasa por unos pocos parece ser operativa con la construcción de una elite nacional, al legitimarse en discursos públicos ${ }^{10}$ como el que nos entrega esta historiografía. Serán aquí los grandes hombres, iluminados, educados y civilizados los encargados de la construcción de la nación y de su dignidad.

$9 \quad$ Veáse Anderson, Benedict (1993), Renan, Ernest (1947) y Ousset, Jean (1980).

$10 \quad$ Véase Larraín, Jorge (1994 y 1996). 
La Centralidad del Discurso del "Héroe" en la Construcción del Mito Nacional: una Lectura de la Historiografía Conservadora desde el Género / Lorena Armijo G.

Este giro conservador es mucho más notable si se considera que, para los criterios de su época, las dos figuras resaltadas, la de O’Higgins y la de Prat, no pertenecían a grupos conservadores ${ }^{11}$.

\section{O’Higgins y Prat como constructores de la nación: una lectura desde el género}

Si bien la idea de nación chilena aparece en las postrimerías del siglo XIX, lo cierto es que podemos encontrar su antecedente directo en la configuración de la idea de la patria libre, la que emergerá a partir de la figura de Bernardo O’Higgins (sobre todo de la interpretación histórica de su figura) y se solidificará con el acto heroico de Arturo Prat en el Combate Naval de Iquique.

El relato que abre la posibilidad de crear un discurso mítico de la nación parte del momento fundacional de una relación amorosa de una mujer y un hombre -Isabel y Ambrosio, padres de Bernardo- quienes servirán como punta de lanza para configurar los imaginarios que enmarcan el discurso historiográfico conservador chileno. A través de ellos es posible narrar la historia de las conquistas, traiciones, desavenencias y uniones de hombres y mujeres que conformaron el mito fundacional de Chile. Es importante este retraimiento a lo privado de la relación informal entre un representante del antiguo régimen colonial y una mujer rural de una zona de escasa densidad política y de una capitanía (Chile) periférica.

Al respecto, el discurso que nos entrega el historiador Jaime Eyzaguirre tiende a comparar a Isabel con las colonias americanas porque ambas habrían sido seducidas por el hombre español y luego despreciadas, siendo una y otra, víctimas de una relación contradictoria de poder que se desarrolla en el marco del goce masculino violento o amoroso de los cuerpos femeninos. En ambos casos (madre y América) hubo una conquista, una empresa, un juego amoroso donde el vencedor fue definitivamente el hombre y el resultado último, dirá Montecino (1992, 1993), será la fecundación de vástagos mestizos. En las explícitas palabras de Eyzaguirre:

“¿Cómo olvidar, aun en medio del innegable placer que le producen las tareas del campo, aquellas preocupaciones que el proselitismo de Miranda dejó prendidas para siempre en su corazón? Habría resultado difícil ahogarlas, y, precisamente ahora, que su inconsciente, activado por la presencia de Doña Isabel parecía moverse con más ímpetu que nunca. Su cariño filial se alimentaba de las humillaciones y vergüenzas sufridas por su madre como consecuencia de una palabra empeñada y no cumplida por un funcionario del rey. Sí, de este mismo monarca que sin miramientos mayores tenía a Chile atado a sus pies. Madre y tierra -que también es madre- sufrían el peso de idéntico victimario y se hacían así una misma cosa. La imagen del padre duro e inflexible

O’Higgins es fundamental en la crítica del antiguo régimen, rompiendo con tradiciones fundamentales que vinculaban la nueva nación a la era colonial. Prat, por su parte, era un abogado liberal. 
se identificaba a su vez con los repliegues de su alma con la de la autoridad despótica, y si la conciencia reflexiva era capaz de adjudicar gratitud y veneración a la memoria del progenitor, los secretos e incontrolados impulsos del inconsciente fundían todo en un solo haz de resentimientos. Jamás supo Don Bernardo hasta dónde sus fervorosos anhelos de ver aplastado el nombre de España en el suelo chileno contenían el deseo de negar la afrenta inferida al honor de su madre" (Eyzaguirre, 1950: 43).

Para el niño Bernardo, su madre sería lo maternal, la presencia de la mujer en la estabilidad de la vida cotidiana; mientras que la imagen paternal es algo más compleja debido a la ambivalencia que le produciría su padre: por un lado, el hijo respeta al progenitor en tanto gobernante y llega a admirarlo, pero, por otro lado, esa imagen de personaje público se funde con la imagen despótica y ausente de su padre. Esta contradicción llena de resentimientos se resolvería aceptando al virrey por sus obras públicas, pero repudiando al padre por su ausencia en la relación filial. En el imaginario de sus padres, Bernardo podrá a futuro reivindicar su origen ilegítimo cuando anhela "ver aplastado el nombre de España”, al mismo tiempo que intentará enaltecer la figura femenina de su madre.

En el origen de O'Higgins se funde la 'escena original' de la cual nos habla Sonia Montecino (1992) la emergencia de una nueva categoría humana: los vástagos mestizos, huachos ilegítimos, huérfanos que son socializados por la madre y su cultura, pero tensionados por su origen en un padre 'blanco'. Se trataría de un hijo huacho que no alcanza la categoría de varón (Morandé, 1984) que se ubica en los estratos más bajos de la sociedad chilena, lo que según Montecino (s/f) significó un estigma que hasta hoy perdura. Este conflicto que supone el origen ilegítimo será resuelto señala Montecino $(1991,1992)$ en la historiografia tradicional que "aceptando que hubo una historia de mestizaje, concubinato, amancebamiento y barraganía, piensa que el sujeto mestizo mayoritariamente optó por el padre asumiendo su cultura y su identidad. El que optó por la madre se habría desplazado a los márgenes de la sociedad (el estrato social más bajo) o vivió en los espacios fronterizos como bandido o aliado de los indígenas" (Montecino, 1992: 42)

Sin embargo, bajo el discurso de la patria libre y -posteriormente- de la nación que aquí revisamos, este mito fundacional del origen ilegítimo podrá ser transvalorado positivamente. Aquí O’Higgins podría míticamente enfrentar y superar al padre español instaurando un nuevo origen, liberado de su padre y del poder político (español) por él representado.Veamos cómo continúa el relato que nos ofrece el historiador:

“Al teñir las primeras luces del alba del 2 de octubre, O’Higgins subió a la torre de la Merced.(...) Sería el cuarto encuentro y de seguro la fiereza de los bandos no se mostraría debilitada en un adarme. Como si nada tuviera de común y fuera sólo razas extrañas e irremisiblemente antagónicas, se precipitarían unos contra otros para destrozarse frenéticos.Y, sin embargo, era la tierra de Chile la madre común de muchos de los que se odiaban.Y sangre de España, de empecinado heroísmo, corría 
La Centralidad del Discurso del "Héroe" en la Construcción del Mito Nacional: una Lectura de la Historiografía Conservadora desde el Género / Lorena Armijo G.

por las venas de todos. ¿Sangre de España? O'Higgins no parecía sentirla, porque grandes rencores y nuevos ideales le tenían ahogado el recuerdo ancestral. Ni esos Riquelmes que lucharon en las guerras centenarias de los moros, ni estos más cercanos espadachines de Chillán, ni la abuela Doña Leonor de Toledo, que defendió la villa contra el asedio de la indiana, tenían sitio alguno en su memoria. Él quería ser el primero de una nueva estirpe brotada del propio esfuerzo y hostil a todo enraizamiento tradicional. Hombre de una edad que nacía cerrando de un golpazo toda comunicación con la historia, no lograba advertir que la cruel venganza del pasado era volverse presente por el atavismo y que, a través de él y de manera invisible, estaban ahora peleando en Rancagua los que hicieron retroceder a la Media Luna en Andalucía y se enfrentaron con la virginidad salvaje de Arauco.'(Eyzaguirre, 1950:139-141. Cursivas agregadas)

O’Higgins intentaría superar la tradición, pero a la vez fundar una nueva. Esto supondría un cuestionamiento al pasado sólido de diversas tradiciones que agrupaba unitariamente a españoles, nativos y mestizos bajo el control y la sangre española. Sin embargo, la tierra era Chile y América. Esta conjunción le plantearía a O’Higgins una sensación de desarraigo: la ambivalencia entre ser español (por su ascendencia Riquelme que peleó contra los moros) y ser chileno. En este escenario, surgiría la búsqueda que rechaza el pasado y que intenta construir un futuro nuevo, una nueva unidad donde nazca y se genere una nueva estirpe que renueve valores, una nueva sangre que reemplace a la antigua de origen español.

Y será precisamente en la guerra donde se articulará el espacio que provocará y ahondará esa división y hará surgir la búsqueda del héroe, quien finalmente pretende transformarla en algo unitario para la nueva estirpe. Es decir, habría en el imaginario sobre O’Higgins una negación y una traición a la herencia española, que se alimenta de la lealtad a la tierra chilena, expresándose así la diferenciación creciente entre los descendientes de españoles en Chile y España.

Ya dijimos que la lucha heroica supone un desgaste simbólico en la construcción de la nación. A continuación veremos como la guerra también posibilita un acto de consagración con la patria:

"Hay instantes en que el desaliento amenaza paralizar la iniciativa y matar la fe en la gran causa. Pero Bernardo reacciona. Tiene, una vez más, en sus manos el pliego de Miranda, y la palabra del maestro sale de allí para reconfortarlo: "No permitáis que jamás se apodere de vuestro ánimo ni el disgusto, ni la desesperación, pues si alguna vez dais entrada a estos sentimientos, os pondréis en la impotencia de servir a vuestra patria. Al contrario, fortaleced vuestro espíritu con la convicción de que no pasará ni un solo día, desde que volváis a vuestro país, sin que ocurran sucesos que os llenen de desconsolantes ideas sobre la dignidad y el juicio de los hombres, aumentándose el abatimiento con la dificultad aparente de poner remedio a aquellos males.....A Amáis a vuestra patria!. Acariciad este sentimiento constantemente, fortificadlo por todos los medios posibles, porque sólo a su duración y a su energía deberéis el hacer el bien. Los obstáculos para servir a vuestro país son tan numerosos, tan formidables, tan invencibles, llegaré a 
Revista de Sociolocía 21 / 2007 Chile Hoy

Facultad de Ciencias Sociales - Universidad de Chile

decir, que sólo el más ardiente amor por vuestra patria podrá sosteneros en vuestros esfuerzos por su felicidad" (Eyzaguirre, 1950: 27. Cursivas agregadas).

Es interesante observar cómo este discurso construye la relación entre O’Higgins y su tierra desde un acercamiento patético. Aquí la patria emergente debe ser amada, servida y de ser necesario también demanda hasta la vida del héroe, quien no dudaría en protegerla. La patria surge de manera gentil, es la inspiración, la gracia, la idealización del sentimiento amoroso y es O'Higgins quien debe ser responsable de ella. De hecho, la patria inspira, pero también obliga, poniendo a prueba el sentido del deber del héroe, haciéndolo reflexionar porque, en definitiva, se trata de expresar lo inexpresable, es una inspiración que pone en cuestión el misterio del encuentro entre la patria (en construcción) y el hombre (su creador).

Esta interpretación nos transporta a la alegoría religiosa de la perfecta unión entre dos amantes, a la alianza amorosa entre Jesús y la Iglesia, entre los cristianos y la Iglesia. Siguiendo el símil religioso, este párrafo no sólo reconstruiría las relaciones entre O’Higgins y la patria, sino que se extiende al resto de los patriotas, incluso reactualizaría el lazo entre el 'nosotros chilenos' y la Patria.Así la patria aparece como la unidad que nos convoca a todos/as bajo un sentimiento de reciprocidad en una relación de intensa afectividad, incluso amorosa. A través de este párrafo podemos vislumbrar la emergencia discursiva de la esencia de la vinculación de los ciudadanos con su país, de los nacionales con su nación que se efectúa desde la experiencia mística de la pertenencia a una comunidad de destino, y no -como podría suponerse en la construcción de la idea de nación- desde un discurso liberal republicano.

Precisamente, esta unión amorosa posibilita la resignificación de la cosmogonía mítica del origen bastardo mediante el reinvento simbólico de la figura materna que permitirá el nacimiento de un nuevo ordenamiento del mundo, y por tanto, de un nuevo destino para los hijos de esa madre. En el discurso conservador analizado emerge un nuevo vínculo de la relación madre/hijo cuyo significado es enaltecido, 'purificado' por el actuar del hijo huacho convertido en héroe que logra transvalorar el pasado ilegítimo al entregarle a la figura materna una nueva 'virtud', una nueva dignidad tan elevada como aquella que posee España, surgiendo así fortificada y enaltecida. Es en estos momentos donde nos distanciamos de la interpretación que Montecino (1991) hace del discurso historiográfico porque justamente la idea de nación que en él se construye permite significar positivamente nuestro origen porque gracias al actuar del héroe ya no seríamos unos 'monstruos mestizos', sino que seríamos patriotas, chilenos y connacionales. Hay por tanto, una legitimidad en nuestro nuevo origen que llega a ser valorado y enaltecido. La bastardía es transmutada en nueva estirpe, posibilidad histórica que se construye desde el pasado y que encuentra en la ilegitimidad originaria el elemento creador de una nueva legitimidad, de los nuevos criterios. 
la Centralidad del Discurso del "Héroe" en la Construcción del Mito Nacional: una lectura de la Historiografía Conservadora desde el Género / Lorena Armijo G.

Y para crear ese nuevo origen se recurre a la madre (y no se habría optado por el padre como afirma Montecino) en una relación que llega a ser simbólicamente incestuosa entre el hijo (héroe) y la madre (patria) que necesariamente requiere de legitimación. Y en este discurso conservador será precisamente la bendición divina la que purificará ese vínculo. Se dice respecto a O'Higgins:

"Se acercaba el momento tan ansiosamente esperado desde hacía más de dos años, en que su espada podría ajustar las cuentas pendientes de Rancagua. (...) Iba con la fe ciega del cruzado de las más grandes de las causas y bajo la resuelta protección de María del Carmelo, que acababa de ser jurada nuevamente generala de las armas de la patria, poco antes de iniciarse la marcha” (Eyzaguirre, 1950:164-169. Cursivas agregadas.)

Como vemos, la presencia de la Virgen es fundamental para delimitar el espacio de lo sagrado en la nación y que no puede ser vulnerado. La Virgen cubre de seguridad el triunfo nacional. Ella es simultáneamente guerrera y madre, es decir, como guerrera legitima simbólicamente el fin de la guerra y el uso de la violencia contra otros, otorgando el triunfo final. Es además madre al proteger a sus hijos de sus enemigos; dilema que finalmente se resuelve al prevalecer su maternidad porque una vez conseguida la victoria, la imagen guerrera desaparece. De todos modos, la imagen de laVirgen nos devuelve nuevamente a la construcción del mito de la nueva estirpe, de ese lazo entre el hijo huacho y la madre, entre el héroe nacional y la patria femenina, entre el pueblo patriota y la Virgen soldado.

Montecino (1991) nos dice que esta virgen madre y guerrera nos remite a la distinción vida/muerte lo que revelaría una tensión entre el pasado agobiante y de muerte, y un presente y futuro seguro, de vida. A nuestro juicio, la presencia de la Virgen en este discurso posibilita el tránsito del conflicto a la paz, de la muerte de los realistas a la vida y multiplicación de patriotas. Es decir, la virgen protege, pero como madre también multiplica sus hijos, los hijos de la nueva estirpe iniciada por O'Higgins.

Es interesante observar que los hijos patriotas acuden a la madre-virgen para construir la nueva estirpe y no al Padre ni a Cristo. Son los hijos quienes le devuelven a ella su ubicación en el triángulo de la Santísima Trinidad (Dios, Hijo, Espíritu Santo), resignificando el vínculo padre/hijo/madre. Aquí la madre actúa protegiendo a su hijo que está luchando contra la figura del padre. Es decir, no se recurre al padre porque contra él es la rebelión, tampoco al hijo porque es precisamente O'Higgins que ataca al padre (ausente y traidor) en alianza con su madre. Lo que ocurre es que se suplica a la madre-virgen en un sentido mágico, incluso supersticioso, depositando en ella la posibilidad de evitar la derrota. Vale decir, el hijo permite la creación de la estirpe, pero la madre la reproduce y la virgen como madre le da dignidad a esa estirpe. Se trata entonces, del restablecimiento de la dignidad de la madre que se ha perdido con el abandono y la traición del padre cuando se simboliza como santa, es decir, cuando ella santifica la estirpe. 
Lo central del discurso de la 'nueva estirpe' que observamos en la historiografia conservadora revisada es que reemplaza el patriarcado anterior por uno nuevo. Se niega la línea de descendencia socialmente reconocida y se construye una nueva, con nuevos padres. Un nuevo origen emerge, cubriéndose la ignominia de la antigua estirpe. El hijo reemplaza al padre al hacerse padre. En eso la historia de Chile penetra en senderos psicoanalíticos. En este nuevo mito fundacional es el hijo quien entra en conflicto y en identificación con el padre, tensión que se consuma con la Independencia donde nace una nueva era en la cual se desconocen los antiguos padres y se reconocen nuevos. Bernardo reemplaza a Ambrosio. El O’higgins hijo simboliza la nueva república, mientras el padre que le dio el apellido (y la formación, pero no mucho más) será el símbolo de la decadencia del viejo orden. Bernardo conserva el liderazgo, la presencia en la historia de su padre, pero ha invertido la fórmula.

Esta interpretación nos recuerda el mito freudiano de la muerte violenta del padre por sus hijos en las hordas primitivas. En el caso latinoamericano, el padre español (el rey y sus funcionarios, el poderío español) estaría acaparando para sí el mundo americano (el privilegio de disponer de las mujeres americanas, las colonias), mientras que sus hijos (los criollos americanos, entre ellos O’Higgins por supuesto) guardaban impulsos de resentimientos contra él porque se oponía a sus intereses y anhelos de poder. Pero los hijos también le temen y admiran. En medio de este escenario surge la guerra independentista que buscará rebelarse contra esa disposición autoritaria de prerrogativas, asesinando al padre español. Sin embargo, una vez muerto e identificándose con él, ninguno de los hijos patriotas ocupó su lugar. Por el contrario, repartieron la tierra (y las mujeres) creando Estados independientes en los cuales cada uno de ellos tendría los mismos privilegios y deberes porque también estaban sometidos a las prohibiciones de cometer el mismo acto (la guerra). En esos momentos, la comunidad fraternal construye un código ético para poder vivir juntos en paz, impidiendo lo que ellos como hijos hicieron con el padre, o sea, desautorizaron su propio acto. Es así como surge la idea de 'hermandad' latinoamericana (¿cómo entender la fraternidad de la región sin recoger el relato filial?). Esta unión se superpone a una lógica de relación de bastardía paterna sumamente clara en O’Higgins. América Latina es hija ilegítima, derivada de la violencia de España y se ha rebelado contra ella, ha conseguido su independencia, pero mantiene una culposa reverencia.

Tiempo después y una vez instalada la patria libre emerge una nueva búsqueda que intenta ubicar a la patria chilena en una posición destacada en el escenario latinoamericano y será precisamente un nuevo héroe el sujeto llamado a responder a una demanda sentida por el liderazgo en la región. A la anterior interpretación sobre el discurso de Eyzaguirre sumo ahora texto que el historiador Gonzalo Vial Correa construye de la figura de Arturo Prat.

"Una frase del héroe, en una de sus cartas desde el Plata sobre la eventual guerra con Argentina, llama la atención. El pacifismo exagerado -asegura- amenaza hacernos "perder 
la Centralidad del Discurso del "Héroe" en la Construcción del Mito Nacional: una Lectura de la Historiografía Conservadora desde el Género / Lorena Armijo G.

la influencia que para nuestra tranquilidad y el bien de América debemos y podemos ejercer (en ésta)...y que no ponemos en práctica por puro egoísmo". Reflejando estas palabras un propósito "americanista" pero de resabios expansivos - un destino americano para Chile-, muy distinto del otro, el sentimental, que sus críticos tachan de entreguista, y cuyo máximo exponente es aquí Vicuña Mackenna” (Vial Correa, 1995: 155. Cursivas agregadas).

Según este discurso, Chile sería superior en términos éticos, políticos y militares al resto de los países latinoamericanos y, por esto, estamos llamados a conducir a la región con el fin de que ellos se asemejen al ideal chileno; se dice que es por "el bien de América". Así, la estirpe llamada Chile, en labios de Prat, estaría llamada a crecer y engrandecerse frente a otras estirpes. Ya no seríamos los hijos patriotas que luchan contra el padre español, sino que seríamos el hijo que exige y reclama superioridad y respeto frente a sus hermanos, sosteniendo una identidad definida y singular. De este modo, el hijo 'Chile' ya ha crecido y se sienta fuerte y 'maduro' y anhela volverse 'un padre' en la conducción internacional de la América Latina.

Este llamado para el héroe debe realizarse en su espacio propio: la guerra. En efecto, la búsqueda del predominio en el escenario internacional le da prestigio a la estirpe y será precisamente, aquel 21 de mayo el día del hito que permitirá que Chile y su héroe naval sean enaltecidos.

"El hombre que no ambiciona gloria, riqueza ni poder; que vive una vida modesta y digna, consagrada a su familia y su trabajo; que hace una regla invariable del amor a la patria y el cumplimiento del deber; y que por esta regla sacrifica meditadamente la vida, ese hombre -Arturo Prat- concita de una manera natural la veneración de los humildes. Que tenga o no tenga éxito, es para ellos un punto secundario; no está ahí el nudo de la cuestión.Y la paradoja más fantástica de la "pratmanía” popular resulta justamente ésa: que le héroe logró éxito, no obstante que "su barco fue destruido y su tripulación capturada o muerta”, y no obstante su propia muerte; que a la verdad logró la victoria por estas precisas circunstancias, en apariencia tan negativa; que ello mueve la admiración de la sociedad culta, civil o uniformada, que analiza lo sucedido...pero en nada influye sobre la admiración popular. Pues el pueblo, instintivamente, descarta las exterioridades -la dominación, el dinero, el triunfo humano, la fama- $y$ va al fondo mismo de las cosas, para discernir inapelablemente quiénes merecen ser propuestos como ejemplos éticos a todas las generaciones" (Vial Correa, 1995: 265. Cursivas agregadas).

El autor señala que en su acto heroico, Prat sólo cumplió con su deber y por ello es reconocido por el pueblo. Sin embargo, en los sectores aristócratas -donde él mismo tuvo su origen- no lo asumió de esa manera. Esto puede interpretarse como sigue: para el pueblo el abordaje al Huáscar y la sucesiva muerte es un acto de grandeza en la derrota porque si bien se trata de una derrota, ellos admiran la grandeza del triunfo que proviene del esfuerzo, del sacrificio por cumplir con el deber. Ellos entienden a Prat como a un igual porque se entrega de la misma manera que ellos a su trabajo y familia, dirá la historiografia conservadora. 
Siguiendo este discurso es posible señalar que la nación emerge como un orden pensado $^{12}$, como una representación que la cultura chilena determina como-unidad, pues sería el pueblo quien decidiría quiénes merecen ser propuestos como ejemplos éticos a todas las generaciones futuras. Bajo su imagen se alza la posibilidad de unirse con un compañerismo profundo y horizontal, que les permite constituirse en torno al 'nosotros arquetípico'13 que se manifiesta como una apropiación de una tradición cultural específica que adquiere sentido en una interpretación social e histórica de sí misma. Así la nación emergería para el Chile popular como la culminación de un largo pasado de esfuerzos, sacrificios y devoción, de deber a la familia y al trabajo. En Prat, el pueblo (aquella estirpe ya construida) puede representarse a sí mismo, como un ejemplo de virtud y como un igual, como lo que se es y a lo que se aspira.

En efecto, en "su arenga espartana" se explicita que la patria depende de cada uno de sus miembros, y de nadie en particular, pues en ninguno queda depositado su honor, su voluntad o su fin último, todos somos convocados y ninguno privilegiado. Veamos a continuación el relato del historiador:

“¡Muchachos: la contienda es desigual!. Nunca nuestra bandera se ha arriado ante el enemigo, espero pues que no sea ésta la ocasión de hacerlo. Mientras yo esté vivo, esa bandera flameará en su lugar, y os aseguro que si muero, mis oficiales sabrán cumplir con su deber. ¡Viva Chile!” (Vial Correa, 1995: 204. Cursivas agregadas).

Su sacrificio se ofrece como la recordación de una proscripción: es imposible rendirse en la defensa de la nación, cuestión que debe privilegiarse ante los intereses y necesidades personales, es decir, el deber y la institucionalidad trascienden a la persona. Tan intensa es esta convicción que la herencia de esta estirpe está garantizada:la muerte del líder tiene correlato en los oficiales, que sabrán cumplir con su deber. Con esto, la institucionalidad o la nación ya no queda depositada en un único sujeto. Aunque muera el último héroe, ellas seguirán funcionando porque su devenir queda depositado en todos/as los/as chilenos/as. Con este discurso, la estirpe se libera del heroísmo y, sin embargo, puede seguir viviendo autónomamente. De ahí tal vez, la estirpe chilena no necesita de más héroes porque ya está institucionalizada, existe por sí misma. En este discurso, el ciudadano común puede llegar a ser Arturo Prat, siempre cuando actúe como él. Así cada uno puede rendirle honores a la nación, al colectivo, a lo que somos en nuestra unidad y deseamos ser a futuro como comunidad. Este mensaje nos conduce a pensar que Chile (y los/as chilenos/as) nunca será una estirpe vencida, porque mientras conserve la dignidad del ejemplo de Prat, el resultado de una batalla perdida puede ser la victoria de la estirpe.

\footnotetext{
Véase, Anderson, Benedict (1993).

13 Véase, Kosselleck, Reinhart en Beriaín, Josetxo (1996).
} 
la Centralidad del Discurso del “Héroe" en la Construcción del Mito Nacional: una Lectura de la Historiografía Conservadora desde el Género / Lorena Armijo G.

\section{Conclusiones}

La cualidad que vincula al héroe con la nación -en el discurso historiográfico conservador chileno revisado- es el sacrificio (la producción de lo sagrado mediante la postergación de sí mismo por una causa), que llega a ser significada por el colectivo con patético orgullo. Este sacrifico se alza como un precio que debe pagar el grupo por la obtención de su libertad y dignidad nacional. Ellos saben que gracias al acto del sacrifico pueden más, sienten una fuerza superior para soportar o enfrentar las adversidades, pues quien los guía conoce los destinos del grupo y sabe por donde guiarlos. Por eso su figura es un lugar común (reconocido e inolvidable) en la construcción de la nación chilena. Pero también en su imagen hay una búsqueda social del lazo histórico: de la vida en común, de lo que vincula, ya que es la estirpe la que modela y construye su futuro. Ese lazo que construye la historiografia conservadora chilena es el valor, la capacidad que permite conjuntamente afrontar y reconocer la historia vivida, percibirse como nación. Es el valor el que posibilita que en momentos dificiles lo mejor de la estirpe se concentre casi mágicamente en algún hombre, en el héroe. De ahí que sea imprescindible la presencia del rol heroico en la historia de Chile. De esta manera, el héroe resuelve la contradicción inicial entre pasado y futuro, mediante una articulación con sentido entre ambos, otorgando y asegurando la continuidad de la nación chilena.

Su capacidad vinculante contribuye a resignificar la cosmogonía reinante, porque mediante su actuar puede renovar valores. La acción del héroe nacional permite hacer una nueva lectura del origen histórico chileno (y también latinoamericano), al reconstruir simbólicamente la síntesis social ya no desde la deshonra y la precariedad de los vínculos entre hombres y mujeres, sino desde la reciprocidad y la sacralidad. El héroe le da un sentido conservador a la transformación, pues vincula simbólicamente lo nuevo y lo antiguo. En este sentido, el rol del héroe es decisivo en una historiografia conservadora que requiere dar arraigo histórico a la contingencia.

A través del vínculo entre héroe/patria se purifica la bastardía original, el 'pecado original' de ser mestizos, productos de una unión ilegítima que nos impidió en el pasado vivir en unidad o comunidad. No obstante, una vez que el 'pecado original' logra ser sustituido con un nuevo origen podemos ser redimidos como hijos, y ser un solo pueblo. En este sentido el origen de O'Higgins es fundamental: este discurso dice que a partir de las mejores características españolas y las principales del pueblo mapuche se construye la nación chilena y sólo un sujeto que escapa a ambos mundos y no obstante, los porta en sí mismo puede crear algo nuevo. Es decir, el origen ilegítimo tiene más que ver con la necesidad de la nueva estirpe. El 'huacho' es ruptura de estirpe y, por tanto, puede ser creación de una. Por eso Bernardo O’Higgins puede ser el padre de la patria, y al mismo tiempo, su heroísmo es manifestación de esa mixtura.

Pero tal como el mito fundacional, el mito de la nación es producto de una relación simbólica incestuosa en la que el hijo huacho es el héroe fundador.Aquí es interesante 
profundizar en las categorías de género porque en ambos textos revisados podemos observar la reconstrucción de lo femenino y masculino desde distintas alegorías: la categoría femenina es reconstruida sexual y amorosamente desde el rol de madre, amante, virgen, y patria; mientras que la masculina puede ser representada en la figura del hijo, el amante, el libertador y padre de la patria. A veces esa relación puede ser leída desde una mirada filial, o sexual, pero prevalece la percepción de hibridez del vínculo, del mestizaje y del incesto.

En términos psicoanalíticos sería la culminación del complejo de Edipo porque con O’Higgins, el hijo se relaciona incestuosamente con la madre, mata al padre y luego niega el incesto erigiendo a la madre como virgen. Luego con Prat este hijo se siente maduro, y retorna o se acerca al padre porque lo que desea es definitivamente ser como el padre en el escenario internacional y utilizará la guerra como espacio ideal para potenciar la imagen autoritaria y dominadora del padre. De este modo, la idea de nación chilena se 'abre' con O’Higgins -quedando pendiente- y sólo se 'cierra' con Prat. La tríada madre/hijo/padre quedaría restablecida con el acto de este último héroe, con lo cual la figura del padre es devuelta, siendo cercana y presente.

Con todo podemos pensar que lo femenino es enaltecido simbólicamente cuando aparece en tanto rol reproductivo. Cualquier otra definición de lo femenino es infravalorada (como puede ser la mujer libertina o la mujer enamorada); mientras que lo masculino alcanza una posición superior en tanto imponga su fuerza, su liderazgo y su interés por el bien del colectivo. Esto queda claramente expuesto cuando el héroe 'exitosamente' actúa siempre de acuerdo al ideal de masculinidad expresado en su heroísmo; su acción desde lo femenino siempre supone su decadencia. En efecto, cada vez que se desea mostrar debilidades de la personalidad de los héroes o momentos de duda existencial y confusión, se remite a feminizaciones de su conducta porque si bien los valores son mostrados como universales, finalmente, son masculinos y el héroe los encarna. Por esto, el acercamiento al mundo femenino por parte del héroe (como la manifestación de sentimientos o la colaboración en las labores domésticas), tiene que efectuarse obligadamente desde su masculinidad, de lo contrario se expone a perder su cualidad heroica.

En este sentido, lo femenino y masculino deben expresarse desde su ideal. Lo femenino emerge positivamente cuando hay una referencia a la comunidad; mientras que lo masculino surge cuando se apela a la unidad. Aquí el sujeto femenino como tal nunca es sustantivo, sino que llega a su plenitud cuando aparece vinculada a la idea de nación; en tanto la encarnación del sujeto en la nación es masculina. De esta manera, lo masculino porta el llamado a crear y engrandecer a la nación, mientras que lo femenino a reproducirla. En ambos casos, si se escapa de los papeles ya establecidos, se corre el riesgo de perder el prestigio social. 
la Centralidad del Discurso del "Héroe" en la Construcción del Mito Nacional: una Lectura de la Historiografía Conservadora desde el Género / Lorena Armijo G.

La historiografia conservadora, en definitiva, lee la historia de Chile como relato religioso que se concentra en una lectura del origen del colectivo y del desenvolvimiento de la historia espiritual de ese colectivo. La construcción de la nación es la constitución y consolidación de una nueva estirpe, que revalorizará el proceso de independencia como construcción de una nueva legitimidad. Es decisivo aquí el hecho de que la subversión simbólica que representa O’Higgins. Muchacho marcado por la bastardía, hijo del pecado, es santificado mediante la transformación del criterio de legitimidad, que arrastra consigo toda la interpretación de la historia. La madre, que en el viejo imaginario transita a la caída moral al entregar su cuerpo sin el sagrado vínculo del matrimonio, es resignificada como la ingenua mujer que creyó las palabras de un hombre respetable e importante. La falta de la madre deja de ser tal y pasa a ser la traición del padre. Este tránsito es de gran sofisticación, porque resulta impropia de una sociedad patriarcal, como lo era intensamente. Por tanto, el proceso de re-legitimación ha de ser muy energético como para haber producido este cambio. El resultado de la relación, el hijo, también cambia de estatus. Un muchacho bastardo, huacho, es el último del antiguo orden (hijo ilegítimo). Sin embargo, en una transmutación notable se convertirá en el primero de la nueva estirpe. Bernardo O'Higgins será entonces el hijo que se convierte en padre, que reemplaza el antiguo orden y santifica las formas que antes eran impuras. Este es un proceso de sacralización que encuentra su apogeo en la interpretación conservadora sobre Arturo Prat, el héroe de Iquique, quien se encuentra con la estirpe ya consolidada, anclada en la familia perfecta (Carmela Carvajal y su amor puro) y desea para América los valores superiores que esta estirpe, la chilena, ha instaurado. La estirpe ya ha superado el momento de origen y ha transitado a ser superior.

\section{Bibliografía}

ANDERSON, Benedict (1993). Comunidades Imaginadas. Reflexiones sobre el origen y la difusión del nacionalismo. Fondo de Cultura Económica, México D.F.

BERIAIN, Josetxo (1996) La integración en las sociedades modernas. Cap. 7. Editorial Anthropos, Madrid.

CRISTI, Renato y RUIZ, Carlos (1992) El pensamiento conservador en Chile. Introducción. Colección Punta de lanza, Editorial Universitaria, Santiago.

CONNELL, Robert (1997) “La organización social de la masculinidad” enVALDES, Teresa y OLAVARRÍA, José (ed) Masculinidades, poder y crisis. ISIS Internacional, Ediciones de la Mujer N²4, Santiago, pp. 31-48.

DURKHEIM, Emile (1992) Las Formas Elementales de laVida Religiosa. Ediciones Akal, Madrid. 
ReVista de Sociolocía 21 / 2007 ChILe Hoy

Facultad de Ciencias Sociales - Universidad de Chile

EYZAGUIRRE, Jaime (1950) O’Higgins. Editorial Zig-Zag, Santiago.

FREUD, Sigmund (1997) “Totem y Tabú” en Obras Completas. Tomo 5. Editorial Biblioteca Nueva, Madrid, pp. 1745-1850.

GELLNER, Ernst (1989). Cultura, Identidad y Política; el nacionalismo y los nuevos cambios sociales. Gedisa, Barcelona.

GODOY, Hernán (1976) El carácter chileno. Editorial Universitaria, Santiago.

LARRAIN, Jorge (1994) La Identidad latinoamericana: teoría e historia en Revista Estudios Públicos, n55, CPU, Santiago.

(1996) Modernidad, Razón e identidad en América Latina Cap. I yVI, Editorial Andrés Bello, Santiago.

MAYOL, Alberto (2005) "Historia e Historiografia en la Construcción de la Identidad Nacional Chilena" (mimeo).

MONTECINO, Sonia (1991) Madres y huachos. Alegoría del mestizaje chileno. Editorial Cuarto Propio/CEDEM, Santiago.

(1992) Presencia y ausencia. Género y mestizaje en Chile. Revista Proposiciones N²1, Ediciones SUR, Santiago.

(s/f) La conquista de las mujeres: mestizos al revés y al derecho. Programa Interdisciplinario de Estudios de Género. U.de Chile, Santiago

OUSSET, Jean (1980) Patria, Nación-Estado. Ediciones del Cruzamante, Buenos Aires.

RENAN, Ernest (1947) ¿Qué es una nación?. Cristianismo y judaísmo. Contemporáneos ilustres. Consejos del sabio. Editorial Elevación, Buenos Aires.

ROCKER, Rudolf (1942) Nacionalismo y cultura. Ediciones Imán, Buenos Aires.

SALAZAR, Gabriel y PINTO, Julio (1999) Historia Contemporánea de Chile. TOMO I. Estado, legitimidad, ciudadanía. Lom Ediciones, Santiago.

VIAL CORREA, Gonzalo (1995) Arturo Prat. Editorial Andrés Bello, Santiago. 